\title{
EL MERCADO COMÚN
}

\author{
Magdalena González Jiménez
}

doi: 10.18543/ed-64(1)-2016pp137-164

\begin{abstract}
SUMARIO: 1. CONSIDERACIONES PREVIAS. 2. El MERCADO INTERIOR EUROPEO. 2.1. La libre circulación de mercancías. 2.2. La libre circulación de trabajadores. 2.3. Derecho de establecimiento y libre prestación de servicios. 2.3.1. El derecho de establecimiento. 2.3.2. La libre prestación de servicios. 2.3.3. Excepciones a ambas libertades. 2.4. La libre circulación de capitales. 2.5. Evolución y desafios pendientes. 3. OTRAS EXPERIENCIAS EN PROCESO DE CONFORMACIÓN. 3.1. El Mercado Común Centroamericano (MCCA). 3.2. La Comunidad del Caribe (CARICOM). 3.3. La Comunidad Andina. 3.4. El Mercado Común del Sur (MERCOSUR). 3.5. La Comunidad Económica Africana (CEA). 3.6. El Mercado Común del África Central y Oriental (COMESA). 3.7. La Asociación de Naciones del Asia Sudoriental (ASEAN). 3.8. El Consejo de Cooperación de los Estados Árabes del Golfo (CCG).
\end{abstract}

\section{CONSIDERACIONES PREVIAS ${ }^{1}$}

El Mercado Común supone un modelo de asociación económica supranacional más avanzado que la Unión Aduanera, pues suma a la libre circulación

${ }^{1}$ Esta publicación se enmarca en las actividades de trabajo que desarrollo como miembro del equipo investigador de la UCLM, del Proyecto: «Constitución y Mercado en la crisis de la integración europea», DER2013-48327-C3-1-R, correspondiente al Programa Estatal de Investigación, Desarrollo e Innovación orientados a los Retos de la Sociedad, del Ministerio de Economía y Competitividad español. Sus investigadores principales son José Luis García Guerrero y María Luz Martínez Alarcón. Se trata, a su vez, del proyecto-coordinador de un grupo de tres subproyectos: el ya mencionado, de la Univer- 
de mercancías -mediante la eliminación de los obstáculos arancelarios y no arancelarios a las importaciones y exportaciones de mercancías originarias de los Estados miembros de la zona, y a la unificación de la política comercial con el exterior mediante el establecimiento de un arancel exterior común para productos procedentes de terceros países-, la liberalización de la circulación de todos los factores que intervienen en el proceso de producción: también las personas, los servicios y los capitales, en base al principio general de no discriminación por razón de nacionalidad y la eliminación de todo tipo de barreras al respecto: técnicas, legislativas, administrativas, etc. Sólo se admiten contadas excepciones por razones de orden público, seguridad y salud pública, que serán objeto de una interpretación restrictiva.

Pese a que otras organizaciones internacionales también aspiran a su consecución, tal y como reseñaremos en la última parte de este trabajo, el Mercado Común o Interior Europeo es, a saber, su única manifestación exitosa, aunque tampoco plenamente acabada. Su estudio constituirá, pues, el objeto principal de este ensayo.

\section{EL MERCADO INTERIOR EUROPEO}

Para el Tribunal Constitucional español, la unidad territorial del mercado español supone, por lo menos, la libertad de circulación sin traba por todo el territorio nacional de bienes, capitales, servicios y mano de obra y la igualdad de las condiciones básicas de ejercicio de la actividad económica ${ }^{2}$. Uno y otro contenido están explícitamente formulados en la Constitución: primeramente, en el apdo. $2 .^{\circ}$ del art. $139 \mathrm{CE}$ : «Ninguna autoridad podrá adoptar medidas que directa o indirectamente obstaculicen la libertad de circulación y establecimiento de las personas y la libre circulación de bienes en todo el territorio español». Pero también en el apdo. $1 .^{\circ}$ de este mismo artículo, donde se contiene una explícita formulación de la igualdad desde la perspectiva territorial referida en general a todo tipo de derechos y deberes, incluidos obviamente los económicos: «Todos los españoles tienen los mismos derechos y obligaciones en cualquier parte del territorio del Estado».

La creación de un mercado único comunitario requiere que el mercado español se abra también a las mercancías, servicios y capitales y a los empresarios y trabajadores procedentes de los demás Estados miembros. Lo que implica limitar las posibilidades de intervención de los poderes públicos españoles sobre el mercado español. En otras palabras, la regulación pública del mercado español está sujeta no sólo a límites constitucionales

sidad de Castilla-La Mancha, y otros dos más, de la Universidad de Deusto y la Universidad Pablo Olavide.

${ }^{2}$ SSTC 88/1986, de 1 de julio, FJ 6. ${ }^{\circ}$, y 64/1990, de 5 de abril, FJ 3. ${ }^{\circ}$. 
internos, sino también a límites externos derivados de la integración de ese mercado en el comunitario, que se concretan, como veremos sucintamente a continuación, en exigencias tanto de igualdad -no discriminación- como de libertad.

En el ámbito de la Unión Europea (UE), el establecimiento del Mercado Interior -o Común- (MI) supone, básicamente, la realización de las libertades de circulación de mercancías, personas, servicios y capitales, esto es, la libertad de circulación intracomunitaria de los diferentes factores productivos para lograr una asignación de los recursos económicos lo más eficaz posible. Estas libertades se completan con un conjunto de normas destinadas a preservar la libre competencia, con la instauración de políticas comunes en algunos sectores económicos y con una política comercial común frente al exterior (como vertiente exterior del mercado común). Dadas las limitaciones de un trabajo de estas características, abordaremos a continuación, sucintamente, lo más significativo de cada una de esas cuatro libertades ${ }^{3}$.

\subsection{La libre circulación de mercancías}

La libre circulación de mercancías, núcleo original del Mercado Interior, está regulada básicamente en los artículos 28 a 37 del Tratado sobre el Funcionamiento de la Unión Europea (TFUE). Estos preceptos contienen, por un lado, prohibiciones encaminadas a la eliminación de los obstáculos, arancelarios o no, que impiden la libre circulación intracomunitaria de mercancías y, por otro, prevén la implantación de un arancel exterior común, convirtiendo así a la UE en una Unión Aduanera.

Los Tratados constitutivos no definen el concepto de mercancía a estos efectos, labor de la que se ha encargado el Tribunal: todo bien estimable en dinero -material o inmaterial-y susceptible de transacción comercial ${ }^{4}$. Lo que sí hacen es excluir expresamente de esta libertad a algunas de ellas, como las armas, municiones y material de guerra destinados a fines específicamente militares [art. 346.1.b) TFUE] o establecer un régimen especial para otras, como los productos agrícolas, para los que las reglas generales se aplican supletoriamente (art. 38.3 TFUE). Obviamente, tampoco se consideran mercancías aquellos bienes o productos cuya comercialización esté prohibida -«res extracomercium»-(como las partes del cuerpo humano).

${ }^{3}$ Nos valdremos como guía para ello, en buena medida, del trabajo de ARCOS VARGAS, M., «El Mercado Interior», en AlCAIDE Fernández, J. y CASAdo RAIGón, R., (Directores), Curso de Derecho de la Unión Europea, Tecnos, Madrid, 2014, pp. 317-349.

${ }^{4}$ Sentencia de 10 de diciembre de 1968, As. 7/68, Comisión c. Italia, Rec. 1968, p. 233. 
La libre circulación se predica de los productos originarios de los Estados miembros y de los productos procedentes de terceros países que se encuentran en «libre práctica» en los Estados miembros (art. 28.2 TFUE) ${ }^{5}$.

La eliminación de los obstáculos y restricciones de carácter arancelario se garantiza por el art. 28, que prevé la adopción de un arancel común en las relaciones de la UE con países terceros y que prohíbe en el comercio intracomunitario los derechos de aduana a la importación y a la exportación, así como las exacciones de efecto equivalente. Los derechos de aduana son toda carga pecuniaria que grava de forma unilateral y exclusiva un producto a su paso por frontera. Se fijan en proporción al valor del bien o de la mercancía, calculado básicamente sobre el valor de la transacción. Por su parte, las exacciones de efecto equivalente a los derechos de aduana han sido definidas por la jurisprudencia del Tribunal como «toda carga pecuniaria que no constituye un derecho de aduana, pero que se impone unilateralmente y sólo al producto importado con el objetivo de alterar el precio de reventa $\rangle^{6}$. La identificación y la constatación del incumplimiento de tales prohibiciones ha generado abundante jurisprudencia en la que el Tribunal ha enfatizado que sólo es admisible el cobro de alguna exacción o gravamen cuando efectivamente se presta un servicio por la importación o exportación del bien o mercancía, pero el gravamen debe ser en función del servicio prestado y no del valor del bien (por ejemplo, un control fitosanitario o un control técnico como la ITV).

En cuanto a los obstáculos no arancelarios, el TFUE también contiene varios preceptos destinados a eliminación. Su tipología es muy abundante, ya que comprende las restricciones cuantitativas a la importación y exportación así como todas las medidas que tengan un efecto equivalente, los monopolios de Estado, los tributos discriminatorios, los obstáculos técnicos, etc. Así, el art. 110 prohíbe los tributos internos que de forma directa o encubierta mejoran la posición competitiva de la producción nacional respecto a los productos importados de otros Estados miembros. Por su parte, el art. 37 no prohíbe los monopolios de producción o de comercialización, pero sí obliga a los Estados a adecuar sus monopolios nacionales de carácter comercial con objeto de excluir toda discriminación de las mercancías provenientes de otros países comunitarios.

${ }^{5}$ Según el art. 29 TFUE, para ser considerado como tal basta que respecto del producto procedente de un país tercero se hayan cumplido las formalidades de importación y percibido los derechos de aduana en cualquier Estado miembro. Una vez importado, dicho producto queda asimilado a los productos originarios en cuanto a su circulación, pero habrá tenido que respetar los intereses públicos y consideraciones sociales que se respetan en la UE.

${ }^{6}$ Sentencia de 1 de julio de 1969, As. 2 y 3/69, Sociaal Fonds voor de Diamantarbeiders c. S.A. Ch. Brachfeld \& Sons et Chougol Diamond Co., Rec. 1969, p. 317. 
Como acabamos de mencionar, quedan prohibidas las restricciones cuantitativas a la importación y exportación, así como todas las medidas que tengan un efecto equivalente (arts. 34 y 35 TFUE), siendo estas últimas, en la práctica, las de mayor alcance. Su definición, ante la indeterminación al respecto de los Tratados Constitutivos, responde fundamentalmente a una elaboración jurisprudencial y doctrinal. Las restricciones cuantitativas, también llamadas contingentes, son toda disposición de un Estado miembro que prohíbe o limita cuantitativamente, actual o potencialmente, el volumen de transacciones comerciales con otros Estados miembros. Y, conforme a la jurisprudencia del Tribunal, las medidas de efecto equivalente son normas internas de índole comercial o reglamentaciones comerciales susceptibles de obstaculizar directa o indirectamente, real o potencialmente, el comercio entre Estados miembros o cuya finalidad es restringir dicho comercio ${ }^{7}$. Inclusive las reglamentaciones comerciales de aplicación indistinta a los productos nacionales e importados, pero cuyo efecto es la restricción del comercio entre los Estados miembros.

Para evitar en lo posible estas medidas de efecto equivalente el Tribunal interpretó del siguiente modo la prohibición: en tanto en cuanto no exista una normativa de la Unión que regule la comercialización de un determinado producto, la regla de oro es el principio de «reconocimiento mutuo», es decir, debe admitirse la comercialización en los demás Estados miembros de cualquier producto que se comercialice legalmente en el territorio de cualquier Estado miembro. Es la conocida como «jurisprudencia Cassis de Dijon» ${ }^{8}$. Por otra parte, se ha realizado un esfuerzo armonizador en aquellos ámbitos susceptibles de generar mayores barreras técnicas en el comercio entre los Estados miembros de la Unión.

Progresivamente, este proceso se acompañó de una nueva filosofía armonizadora menos burocrática y formalista y más centrada en la calidad que en la cantidad de normas: la armonización se limitaría al mínimo necesario y de forma proporcionada a los objetivos. De esta forma, las directivas fueron más generales y horizontales, por categorías de productos o riesgos, especificando los requisitos exigidos para la comercialización de los bienes en toda la Unión y un procedimiento de certificación. El proceso de estandarización se puso en manos de entes privados, organismos comunitarios como el CEN (Comité Européen de Normalisation), CENELEC (Comité Européen de Normalisation Electrotechnique) y ETSI (European Telecommuni-

7 Sentencia de 11 de julio de 1974, As. 8/1974, Procureur du Roi c. Benoît et Gustave Dassonville, Rec. 1974, p. 383.

${ }^{8}$ Sentencia de 20 de febrero de 1979, As. 120/78, Rewe-Zentral AG c. Bundesmonopolverwaltung für Branntwein, Rec. 1978, p. 371. 
cations Standards Institute), que agrupaban a las correspondientes asociaciones nacionales?.

Los propios Tratados constitutivos permiten excepciones a la aplicación de las reglas generales sobre la libre circulación de mercancías. Como tales, habrán de ser objeto de interpretación restrictiva. Las clasificaremos en tres grandes categorías ${ }^{10}$ :

- Objetivos de interés nacional (art. 36 TFUE). Los Estados miembros pueden prohibir o restringir el comercio con otros Estados miembros «por razones de orden público, moralidad y seguridad públicas, protección de la salud y vida de las personas y los animales, preservación de los vegetales, protección del patrimonio artístico, histórico o arqueológico nacional o protección de la propiedad industrial y comercial». Pero tales prohibiciones no deben «constituir un medio de discriminación arbitraria ni una restricción encubierta del comercio entre los Estados miembros».

- Las «exigencias imperativas». De determinación jurisprudencial, únicamente se acepta su alegación si no hay una norma de la Unión que prevea las prescripciones técnicas y, en todo caso, si se aplican sin discriminación por razón de nacionalidad. Pocas prosperan en la práctica.

- Excepciones a las medidas de armonización (art. 114.4 a 9 TFUE). Se autoriza a los Estados miembros a mantener o establecer disposiciones nacionales que se apartan de una medida de armonización y producen efectos discriminatorios, para proteger el medio de trabajo o el medio ambiente. Siempre son excepciones temporales y, en principio, deben ser aprobadas por la Comisión tras su previa comprobación de que no se trata de un medio de discriminación arbitraria o una restricción encubierta al comercio entre Estados miembros o un obstáculo para el funcionamiento del mercado interior. El abuso de estas facultades por un Estado miembro permite, como excepción al procedimiento normal del recurso por incumplimiento, recurrir directamente al Tribunal.

${ }^{9}$ Calviño Santamaría, N.: «Concepto, evolución y nuevos desafíos para el mercado único», en Beneyto Pérez, J. M.a (Director), Tratado de Derecho y Políticas de la Unión Europea, Tomo VI (Mercado Único Europeo y Unión Económica y Monetaria), Thomson Reuters, Navarra, 2013, p. 43. Vid. más ampliamente sobre el tema, GoNZÁLEZ VAQUÉ, L.: «Armonización y normalización», en ibídem, pp. 617 a 683.

${ }^{10}$ Siguiendo a Arcos Vargas, M., «El Mercado Interior», en Alcaide Fernández, J. y CASAdo Raigón, R., (Directores), Curso de Derecho de la Unión Europea, cit., pp. 329-330. 


\subsection{La libre circulación de trabajadores}

En los inicios del proceso de integración europea, el derecho de desplazamiento y residencia se incluía en el contexto de la libre circulación de personas dentro de la consecución del mercado interior y se vinculaba estrechamente con el ejercicio de actividades económicas transfronterizas. Con la entrada en vigor del Tratado de la Unión Europea, el derecho de desplazamiento y residencia se configura como un derecho individual del ciudadano europeo, autónomo y de carácter político, abandonando su consideración de derecho instrumental vinculado al ejercicio de una actividad económica ${ }^{11}$. Ello podría hacer pensar que la libre circulación de trabajadores habría quedado desdibujada, cuando no es del todo así.

La libre circulación de trabajadores consiste en la libre circulación de los nacionales de los Estados miembros que se desplazan a trabajar por cuenta ajena a otro Estado miembro, e implica que no pueden ser discriminados por razón de nacionalidad respecto al empleo, la retribución y las demás condiciones de trabajo (art. 45.2 TFUE). Ello no obstante, en algunas Actas de Adhesión de nuevos Estados miembros se han establecido unos períodos transitorios, más o menos prolongados, durante los que los nacionales de esos Estados no han podido beneficiarse de la libre circulación como trabajadores, aunque sí del derecho a circular y residir libremente en tanto que ciudadanos de la Unión. Adicionalmente, también son beneficiarios de esta libertad los nacionales de determinados terceros países con los que la Unión Europea tiene acuerdos de asociación o cooperación, en especial los integrantes del Espacio Económico Europeo (EEE).

Los Tratados constitutivos no definen el concepto de «trabajador», tarea de la que se ha encargado el Tribunal. Su característica esencial es realizar labores bajo la dirección de otra persona (empleador), a cambio de una remuneración. El resto de condiciones contractuales resulta irrelevante a estos efectos: duración, jornada a tiempo completo o parcial, cuantía de la remuneración, etc.

Progresivamente, a través de la jurisprudencia del Tribunal y el Derecho derivado, fue ampliándose el ámbito de personas con derecho a la libertad de circulación y residencia, haciéndose más difuso el límite entre la libre circulación de trabajadores (o servicios) y la libre circulación de personas. Así, y con base previa en la jurisprudencia del Tribunal, el Reglamento 1612/68, de 15 de octubre de 1968, extendió estos derechos a los familiares del trabajador asalariado migrante, independientemente de su nacionalidad: cónyuge $-\mathrm{y}$

11 Olesti Rayo, A., «Libre circulación de personas: desplazamiento y residencia», en Beneyto PÉrez, J. M. a (Director), Tratado de Derecho y Políticas de la Unión Europea, Tomo VI (Mercado Único Europeo y Unión Económica y Monetaria), cit., p. 385. 
hoy también pareja con unión registrada con arreglo al Estado miembro de su nacionalidad-, descendientes menores de veintiún años y los mayores a cargo del trabajador (o de su pareja) y los ascendientes a su cargo. No obstante, este Reglamento permitió que el Estado miembro exigiera al trabajador disponer de un alojamiento adecuado.

Con posterioridad, las Directivas 90/364/CEE, 90/365/CEE y 90/366/ CEE, relativas respectivamente al derecho de residencia, derecho de residencia de los trabajadores por cuenta ajena o por cuenta propia que hayan dejado de ejercer su actividad profesional y al derecho de residencia de los estudiantes, sustituidas por la Directiva 2004/38, de 29 de abril de $2004^{12}$, distinguieron entre el derecho de circulación y residencia de hasta tres meses, el derecho de residencia superior a tres meses y el derecho de residencia permanente, imponiendo dos condiciones básicas para aquellos nacionales que se desplazasen y de los que no pudiera presumirse de entrada recursos económicos: la obligación de demostrar su solvencia económica y una cobertura suficiente que garantizase que no se convirtieran en una carga para el Estado miembro de acogida.

La libre circulación de trabajadores cubre cualquier actividad susceptible de realizarse por cuenta ajena, sin exclusión de ningún sector salvo el de los empleos en la Administración Pública (art. 45.4 TFUE): cualquier actividad que se efectúe efectivamente, con un valor económico, independientemente de la relación pública o privada y del montante de la remuneración.

La excepción del empleo público ha sido interpretada por el Tribunal desde la autonomía del Derecho de la Unión Europea (DUE), al margen por tanto de las calificaciones que los empleos tengan a la luz de los Derechos internos de los Estados miembros. Y, además, de forma restrictiva, exclusivamente en relación a empleos que implican el desempeño de funciones estrechamente relacionadas con el ejercicio de la soberanía, comportando una participación directa o indirecta en el ejercicio del poder público. No se trata pues de una restricción general de cualquier empleo en la Administración Pública ${ }^{13}$.

${ }^{12}$ El cambio gradual producido en el ámbito de aplicación del derecho de desplazamiento y residencia provocó una liberalización sectorial y fragmentaria del derecho de desplazamiento y residencia, con una multitud de normas comunitarias que trataban separadamente las diferentes categorías de beneficiarios. La aprobación de la Directiva 2004/38 de 29 de abril de 2004, supera este enfoque incompleto facilitando y simplificando el ejercicio del desplazamiento y residencia y reforzando la posición del ciudadano europeo y su familia; dando solución, además, a algunos problemas suscitados sobre el derecho de residencia e incorporando gran parte de la jurisprudencia comunitaria al respecto, ibidem, pp. 385-386.

13 Sentencia de 17 de diciembre de 1980, As. 149/79, Comisión c. Bélgica, Rec. 1980, p. 1291. 
La libre circulación de trabajadores se concreta en el principio de no discriminación por razón de la nacionalidad entre los trabajadores de los Estados miembros con respecto al empleo, la retribución y las demás condiciones de trabajo. Más concretamente, de conformidad con el art. 45.3 TFUE y la Directiva 2004/38, no son admisibles restricciones por razón de nacionalidad en relación al derecho a entrar en el territorio de un Estado miembro para responder a ofertas efectivas de trabajo, o al de residir en él una vez conseguido el empleo. En este último caso, de conformidad con la Directiva 2004/38, el Estado miembro en el que se reside sólo puede exigir «formalidades administrativas», y a los familiares no ciudadanos de la Unión, la tramitación de tarjetas de residencia de familiar de ciudadano de la Unión.

Quedan prohibidas las reservas de «cuotas nacionales» en cualquier empleo o sector (caso Bosman) ${ }^{14}$. Y, adicionalmente, la no discriminación en las condiciones de trabajo se amplió hacia el derecho a disfrutar de ciertas ventajas sociales o el reconocimiento de algunos derechos ligados estrechamente a la persona, entendiéndose por tales ventajas sociales cualquier ventaja social aplicable al trabajador o a su familia, entre otros, el disfrute de los centros de formación, afiliación a sindicatos y derechos sindicales, alojamiento, becas, subsidios, etc.

Obviamente, el ejercicio de estos derechos requiere de medidas complementarias de cooperación interestatal ya que, por ejemplo, las oficinas de empleo y los sistemas de prestaciones de la Seguridad Social siguen siendo nacionales: como la compensación entre demandas y ofertas de trabajo a través de los enlaces EURES. En este mismo sentido, el art. 48 TFUE prevé la adopción de las medidas necesarias para permitir la acumulación de los períodos de cotización y el pago de las prestaciones de Seguridad Social a las personas que residan en los territorios de los Estados miembros. También existen normas de la Unión para la coordinación de otros aspectos de los sistemas nacionales de Seguridad Social.

Como situación diferenciada a los empleos que están excluidos de la libre circulación de trabajadores, los Tratados constitutivos permiten establecer excepciones a la aplicación de los derechos contenidos en esta libertad por razones de orden público, seguridad y salud públicas (art. 45.3 TFUE). Necesariamente tendrán que ser objeto de una interpretación restrictiva y de aplicación a comportamientos individuales del trabajador o sus familiares. Nunca podrán fundamentar una discriminación por razón de nacionalidad, es decir, en ningún caso podrán utilizarse para prohibir en un Estado miembro a los trabajadores migrantes nacionales de otros

\footnotetext{
${ }^{14}$ Sentencia del TJCE de 15 de diciembre de 1995, As C-415/93, Bosman.
} 
Estados miembros actividades que sí se permiten a sus nacionales (asunto Van Duyn, $\left.1974^{15}\right)$.

Como resulta obvio, algunas de las razones que fundamentan estas excepciones son más fácilmente objetivables que otras: por ejemplo, las razones de salud pública pueden concretarse en enfermedades de potencial epidémico según la Organización Mundial de la Salud (OMS), mientras que las razones de orden público y seguridad son objeto de apreciación a través de criterios internos, nacionales.

\subsection{Derecho de establecimiento y libre prestación de servicios}

El sector servicios representa casi un 70\% del PIB europeo y genera nueve de cada diez empleos, lo que da cuenta de la importancia de estas dos libertades. Su desarrollo ha seguido un ritmo mucho más lento y dificultoso que las anteriores, con lo que completar el mismo sigue siendo uno de los mayores retos para el mercado interior europeo. Y ello a pesar de que desde 1974 el Tribunal declaró el efecto directo de las disposiciones de los Tratados constitutivos por las que se prohíbe toda discriminación por razón de nacionalidad, aunque no estuviera desarrollada mediante las directivas previstas 0 éstas no se hubieran transpuesto (asunto Reyners, de 1974) ${ }^{16}$.

Reguladas en los arts. 49 a 62 TFUE, presentan algunos rasgos comunes ${ }^{17}$. En primer lugar, sus beneficiarios son las personas físicas -trabajadores por cuenta propia o profesionales autónomos- nacionales de los Estados miembros o, con base en los Tratados constitutivos y en acuerdos internacionales, de terceros países; y las empresas y sociedades constituidas conforme a la legislación de cada Estado miembro y con sede dentro de la Unión, entendiéndose por sociedades las «sociedades de Derecho civil o mercantil, incluso las sociedades cooperativas, y las demás personas jurídicas de Derecho público o privado, con excepción de las que no persigan un fin lucrativo (art. 54 TFUE)». Al igual que sucede con los criterios de atribución de la nacionalidad a las personas físicas, cada Estado miembro es libre de establecer en su ordenamiento interno los criterios que estime más apropiados para la constitución de sociedades y el resto de los Estados miembros están obligados a su reconocimiento (principio de reconocimiento mutuo). Lo que el art. 54 TFUE requiere es una conexión permanente de la sociedad con un

${ }_{15}$ Sentencia TJCE de 12 de diciembre de 1974, As. 41/74, Van Duyn, Rec. 1974, p. 529.

${ }^{16}$ Sentencia del TJCE de 21 de junio de 1974, As. 2/74, Reyners, Rec. 1974, p. 293.

17 Siguiendo a Arcos Vargas, M., «El Mercado Interior», en AlCaide FernándeZ, J. y Casado Raigón, R., (Directores), Curso de Derecho de la Unión Europea, cit., pp. 337-338. 
Estado miembro expresada, de forma acumulativa, en dos exigencias: su constitución de conformidad con la legislación de un Estado miembro, y que su sede social, administración central o centro de actividad principal radique en el territorio de la Unión.

No obstante lo anterior, y pese que la legislación sobre sociedades sigue siendo eminentemente nacional, se han ido sucediendo bastantes normas comunitarias armonizadoras de aspectos concretos como fusiones, contabilidad, etc. A lo que habría que añadir las figuras de las «Sociedades Anónimas Europeas» y de las «Sociedades Cooperativas Europeas». Más concretamente, el Reglamento 2157/2001, completado con la Directiva 2001/86, ambos de 8 de octubre, y en vigor desde octubre de 2004, fijan los fundamentos de la que denominan «Sociedad Anónima Europea», facilitando la creación de sociedades anónimas transnacionales. Y, respectivamente, el Reglamento $1435 / 2003$ y la Directiva 2003/72, ambos de 22 de julio y en vigor desde agosto de 2006, hacen lo propio con la figura de la Sociedad Cooperativa Europea.

En segundo lugar, pretenden evitar la discriminación entre nacionales de los Estados miembros, o empresas o sociedades constituidas y con sede en un Estado miembro, sea para establecerse y ejercer en otro Estado miembro actividades económicas no asalariadas, es decir, que implican una remuneración a cambio y se realizan por cuenta propia: derecho de establecimiento; o sea para el ejercicio temporal en otro Estado miembro de tales actividades económicas no asalariadas: libre prestación de servicios. La diferencia entre ambas libertades radica pues en la integración más o menos duradera en la vida económica del otro Estado miembro.

En tercer lugar, quedan excluidas de su ámbito de aplicación las actividades en las que se ejerce poder público: las actividades que estén relacionadas, aunque sólo sea de manera ocasional, con el ejercicio del poder público (art. 51 TFUE).

\subsubsection{El derecho de establecimiento}

El derecho de establecimiento (arts. 49 a 55 TFUE) es el derecho de todo trabajador por cuenta propia o profesional autónomo nacional de un Estado miembro y toda empresa o sociedad constituida y con sede en un Estado miembro a establecerse en el territorio de otro Estado miembro para realizar actividades no asalariadas en las mismas condiciones que el Estado receptor exige para sus nacionales o las empresas y sociedades constituidas y con sede en su territorio, incluyendo el derecho a abrir agencias, filiales o sucursales sin discriminación en razón de nacionalidad (art. 49 TFUE).

El Tribunal ha definido el «establecimiento» como «el ejercicio efectivo de una actividad económica, por medio de una instalación permanente, en un 
Estado diferente al de origen (asunto Factortame, 1991)» ${ }^{18}$. Podrá ser principal o secundario -«agencias, sucursales o filiales» según los Tratados constitutivos-.

Los Tratados constitutivos establecen que el derecho de desplazamiento comprenderá «el acceso a actividades no asalariadas y su ejercicio» (arts. 49 y 53.1 TFUE). El contenido básico de esta libertad es la prohibición de restricciones y discriminaciones por razón de la nacionalidad, basándose por tanto en el principio de igualdad de trato con el nacional, incluido el trato de nacional en lo que respecta a la participación financiera de los nacionales de los demás Estados miembros en el capital de las sociedades (art. 55 TFUE).

\subsubsection{La libre prestación de servicios}

Prevista en los arts. 56 a 62 TFUE, consiste en el ejercicio por los nacionales de los Estados miembros establecidos en un Estado miembro, de actividades y profesiones, por cuenta propia y con fines lucrativos, en cualquier otro Estado miembro distinto del de establecimiento, sin que ese otro Estado miembro exija más requisitos o condiciones de los exigidos a los propios nacionales. Subrayemos a continuación los rasgos más importantes de la definición anterior.

En primer lugar, esta libertad presupone que el prestador del servicio está ya establecido en el territorio de la Unión, sea en el Estado del que es nacional u otro, no importa. En segundo lugar, y a diferencia del derecho de establecimiento, se trata de la prestación temporal de un servicio, sin vocación de permanencia, al igual que el profesional tampoco tiene voluntad de integración en la vida económica del Estado miembro en el que presta el servicio. Resulta significativo que los Tratados constitutivos prevean la posibilidad de extender los beneficios de esta libertad a los prestadores de servicios nacionales de un tercer Estado, pero establecidos dentro de la Unión (art. 56 TFUE). En tercer lugar, debe implicar el ejercicio de la actividad de manera transnacional, lo que no comporta que sea siempre el prestador el que deba trasladarse a otro Estado miembro para prestar el servicio: cabe también que se desplace el destinatario o simplemente la prestación (asesoramiento jurídico a través del teléfono, de las TICs, etc.). En ninguno de estos casos podrá restringirse la libre prestación (art. 56 TFUE), pero en tanto se suprimen, las restricciones se aplicarán sin distinción de la nacionalidad o residencia de los prestadores de esos servicios transfronterizos (art. 61 TFUE).

Las actividades amparadas son sólo las ejercidas con la finalidad de prestar un «servicio». Los Tratados constitutivos consideran como tales servicios

18 Sentencia del TJCE, de 25 de junio de 1991, As.C-221/89, The Queen c. Secretary of State for Transport, ex parte Factortame Ltd. y otros, Rec. 1991, p. I-3905. 
«las prestaciones realizadas normalmente a cambio de una remuneración», en particular actividades de carácter industrial o mercantil, actividades artesanales o actividades propias de las profesiones liberales (art. 57 TFUE). En realidad, los Tratados constitutivos consideran la libre prestación de servicios como una libertad residual, pues si la prestación remunerada es susceptible de regirse por las disposiciones relativas a la libre prestación de mercancías, capitales o trabajadores, serán éstas por las que se regirá y, además, la prestación de un servicio se hará «sin perjuicio del... derecho de establecimiento (art. 57 TFUE)». Igualmente ocurre con los servicios en materia de transportes, que se regirán por las disposiciones relativas a la política de transportes (art. 58.1 TFUE), pero no tanto con los servicios bancarios y de seguros vinculados a los movimientos de capitales, cuya liberalización «se realizará en armonía con la liberalización de la circulación de capitales (art. 58.2 TFUE). Por el contrario, cuando un nacional de un Estado miembro establecido en un Estado miembro ejerce una determinada actividad en otro Estado miembro que no corresponde a otras libertades, el Tribunal suele calificar dicha actividad como prestación de servicios ${ }^{19}$.

\subsubsection{Excepciones a ambas libertades}

$\mathrm{Al}$ igual que sucedía con respecto a otras libertades, también razones de orden público, seguridad y salud públicas podrían justificar medidas legales, reglamentarias y administrativas nacionales que establezcan un trato diferenciado para los extranjeros (nacionales de otros Estados miembros y de terceros países), que excepcionalmente serán conformes al DUE (art. 52 TFUE y, para las restricciones al derecho de establecimiento, también el art. 65.2 TFUE). Adicionalmente y de forma progresiva, el Tribunal ha ido reconociendo también al respecto medidas nacionales adoptadas por «razones imperiosas de interés general $\gg^{20}$ siempre y cuando cumplan determinados requisitos acumulativos: su aplicabilidad a toda persona que ejerza la actividad en el territorio del Estado, sin discriminación por nacionalidad; han de ser objetivamente necesarias y proporcionales al interés general que las justifica, adoptándose como última ratio y por causas de urgencia; no es posible su adopción sin antes comprobar que el interés está suficientemente protegido por las normas existentes; su adopción sólo será posible en ausencia de una legislación de la Unión que haya armonizado la prestación del servicio en cuestión.

19 Arcos Vargas, M., «El Mercado Interior», en Alcaide Fernández, J. y CASAdo RAIGÓn, R., (Directores), Curso de Derecho de la Unión Europea, cit., p. 343.

${ }^{20}$ Sentencia del TJCE, de 3 de diciembre de 1974, As. 33/74, Johannes Henricus Maria Van Binsbergen c. Bestuur van de Bedriifsvererniging voor de Metaalnijverheid, Rec. 1974, p. 507. 


\subsection{La libre circulación de capitales}

Dado que los pagos corrientes se liberalizan al mismo tiempo que la transacción que les sirve de base, eventualmente con la única limitación del control de cambios en transacciones que no se realizan en euros exclusivamente, los movimientos de capital son los que interesan especialmente como ámbito de aplicación material de esta libertad. Estos han sido definidos por el Tribunal como «operaciones financieras que pretenden esencialmente la colocación o inversión del montante en cuestión y no la remuneración de una prestación» (asunto Luisi y Carbone, 1984) ${ }^{21}$ por lo que el objeto material del negocio jurídico es el dinero en sí.

En el originario TCEE se preveía la progresiva liberalización del movimiento de capitales, pero «en la medida que fuera necesario para el buen funcionamiento del mercado común», lo que ralentizaba el proceso en comparación con las otras libertades, previéndose además su desarrollo mediante directivas. No obstante, a partir de 1995 el Tribunal confirmó el efecto directo de las disposiciones relativas a la libre circulación de capitales (asunto Bordessa, 1995) ${ }^{22}$.

Las primeras directivas liberalizadoras, de carácter parcial, datan de 1960, pero no será hasta la tercera fase del establecimiento de la Unión Económica y Monetaria (1999-2002) cuando quede prohibida cualquier restricción a los movimientos de capital entre Estados miembros o entre éstos y países terceros (actual art. 63 TFUE). Sólo se permiten ciertas restricciones existentes con destino a terceros países o procedentes de ellos, que supongan inversiones directas, incluidas las inmobiliarias, la prestación de servicios financieros o la admisión de valores en los mercados de capitales (art. 64.1 TFUE) e, incluso, un retroceso en el Derecho de la Unión Europea respecto de la liberalización de esos movimientos de capitales (arts. 64.3, 65.4 y 66 TFUE), pero se establece el objetivo de alcanzar la libre circulación de capitales entre Estados miembros y países terceros en el «mayor grado posible» (art. 64.2 TFUE).

Sin perjuicio de lo anterior, y de conformidad con el art. 65 TFUE, ninguna de las disposiciones relativas a la liberalización del movimiento de capitales impide a cualquier Estado miembro aplicar disposiciones de su Derecho fiscal que distingan en función del lugar de residencia del contribuyente, ni medidas necesarias para impedir las infracciones de su legislación nacional,

${ }^{21}$ Sentencia del TJCE de 31 de enero de 1984, As. 286/82 y 26/83, Graziana Luisi y Giuseppe Carbone c. Ministero del Tesoro, Rec. 1984, p. 113.

${ }_{22}$ Sentencia del TJCE de 23 de diciembre de 1995, As. C-358/93 y C-416/ 93, Procédures pénales c. Aldo Bordessa et Vicente Mari Mellado et Concepción Barbero Maestre, Rec. 1995, p. I-361. 
en particular en materia fiscal o de supervisión prudencial de entidades financieras, establecer procedimientos de declaración de movimientos de capitales a efectos de información administrativa o estadística o tomar medidas o restricciones a la libre circulación de capitales por razones de orden público o de seguridad pública, normalmente para evitar el blanqueo de capitales. Pero tanto en uno como en otro caso, en respeto al objetivo principal del mercado interior, ninguna podrá suponer una discriminación arbitraria ni encubierta en razón de nacionalidad.

Por último, y dado que en el marco de la Unión Económica y Monetaria los Estados miembros de la zona euro ya no son los que pueden adoptar las medidas de salvaguarda necesarias, el art. 66 TFUE establece que, cuando en circunstancias excepcionales los movimientos de capital con terceros países causen o puedan causar dificultades graves para el funcionamiento de la Unión Económica y Monetaria, el Consejo, a propuesta de la Comisión y tras consultar al BCE, puede adoptar las medidas de salvaguardia estrictamente necesarias.

\subsection{Evolución y desafíos pendientes}

El Mercado Interior constituye uno de los pilares fundamentales del proyecto de construcción europea y el núcleo vertebrador de su integración económica. Se concibe como una gran política de oferta cuyos efectos microeconómicos derivados de la integración del mercado (disminución de los costes y la mayor presión competitiva) desencadenan a medio plazo un impacto en las principales variables macroeconómicas, estimulando la competitividad, el crecimiento y la creación de empleo.

El hecho de que dicha meta se haya alcanzado en gran medida constituye uno de los mayores éxitos de la Unión Europea, pero es un proceso inacabado y en continua evolución que todavía no está completo en muchos ámbitos (servicios, integración financiera) y muestra problemas de funcionamiento en áreas en las que, por haberse completado su marco normativo, debería estar ya plenamente operativo (libre circulación de mercancías, detectándose aún barreras técnicas en algunos sectores, barreras fiscales y dificultades de acceso a los mercados públicos).

Estas deficiencias afloraron con mayor intensidad como consecuencia de la crisis económica y financiera internacional, iniciada en 2007 -y cuya superación es en el momento actual el principal reto del proyecto europeo- ralentizando acusadamente la integración en los últimos años en contraste con los logros de la década de los noventa. Como muestra estos datos del conjunto de la Unión a principios de 2010: el PIB cayó un 4\% en 2009 y nuestra producción industrial retrocedió a los niveles de los años 90; 23 millones de europeos en paro (el 10\% de su población activa); las empresas y familias con ingentes dificultades para obtener créditos e invertir; nuestras finanzas 
públicas gravemente afectadas, con un déficit medio del $7 \%$ del PIB y niveles de deuda superiores al $80 \%$ del PIB. Resumiendo: nuestro potencial de crecimiento reducido a la mitad.

La crisis económica ha puesto de manifiesto algunas carencias muy importantes del proyecto de integración europea, en especial, la fragilidad institucional de la Unión Económica y Monetaria, un primer reto de gran calado que se está tratando de acometer en el presente.

Otro gran desafío, estrechamente interrelacionado con el anterior, es el relativo a la necesidad de impulsar el desarrollo económico para poder atender las distintas demandas sociales. Lo exige, sin duda, la superación de la crisis económica más grave que sufrido la UE desde su creación, pero también cambios de distinto orden en el panorama internacional: la mayor competencia global, la presión sobre los recursos naturales y el envejecimiento demográfico, entre otros ${ }^{23}$.

$\mathrm{Y}$ el entorno actual es mucho más complejo y hostil hacia las políticas del MI que en el pasado, con fundados interrogantes sobre la idoneidad de las mismas tal y como han sido concebidas hasta ahora. La mayor complejidad es fruto, principalmente, de las sucesivas ampliaciones de la UE -de 12 miembros en 1986 a los 28 actuales-y su correlativo aumento de la diversidad de preferencias políticas y objetivos integradores. Por otra parte, el contexto hostil se manifiesta en las tendencias proteccionistas derivadas de la crisis, y mucho más allá, al incorporar factores ideológicos: en este sentido, existe en la actualidad mucha mayor desconfianza hacia los mecanismos autorreguladores del mercado y hacia el proceso de integración europea en general («fatiga integradora»), como se manifestó en diversos referéndums para la ratificación del fallido Tratado de Constitución europea ${ }^{24}$.

Como señalaba DELORS en el Libro Blanco de la Comisión del Mercado Interior de 1985, dirigido al Consejo Europeo de Milán: «nadie se enamora de un mercado». Sin embargo, durante décadas se dio por supuesto el apoyo social al proceso de liberalización económica, pensando que los beneficios económicos del buen funcionamiento de los mercados en términos de precios y oferta legitimarían por sí solos el avance. Pero el proyecto europeo necesita fundamentarse sobre el compromiso de la sociedad que reclama el necesario equilibrio entre eficiencia económica y justicia social ${ }^{25}$.

23 JoRdÁn GALdUf, J. M. a y CARdona Llorens, J., «Balance y retos actuales de la integración europea», en AA.VV., La encrucijada de Europa. Luces y sombras para un futuro común, Universitat de València, Valencia, 2015, pp. 139-142.

${ }^{24}$ Roca Zamora, A., «El estado del mercado único: un relanzamiento necesario. Balance y desafíos pendientes», Investigaciones Regionales, n. ${ }^{\circ}$ 18, 2010, p. 181.

${ }^{25}$ CAlviño Santamaría, N., «Concepto, evolución y nuevos desafíos para el mercado único», en Beneyto Pérez, J.M. ${ }^{a}$ (Director), Tratado de Derecho y Políticas de la 
En este sentido, el Tratado de Lisboa introduce un cambio de alcance en los objetivos de la Unión que obliga a replantear las políticas del MI a fin de incorporar una visión mucho más amplia e integradora de sensibilidades -preocupación social y medioambiental- las cuales, precisamente, están en el origen del rechazo ideológico a las políticas de MI realizadas hasta aho$\mathrm{ra}^{26}$ : en concreto, el nuevo art. 3.3 del Tratado de la Unión Europea (TUE) prescribe:

«La Unión establecerá un mercado interior. Obrará en pro del desarrollo sostenible de Europa basado en un crecimiento económico equilibrado y en la estabilidad de los precios, en una economía social de mercado altamente competitiva, tendente al pleno empleo y al progreso social, y en un nivel elevado de protección y mejora de la calidad del medio ambiente. Asimismo, promoverá el progreso científico y técnico.

La Unión combatirá la exclusión social y la discriminación y fomentará la justicia y la protección sociales, la igualdad entre mujeres y hombres, la solidaridad entre las generaciones y la protección de los derechos del niño.

La Unión fomentará la cohesión económica, social y territorial y la solidaridad entre los Estados miembros.

La Unión respetará la riqueza de su diversidad cultural y lingüística y velará por la conservación y el desarrollo del patrimonio cultural europeo».

Ello precisará de un análisis en profundidad de las repercusiones sociales de la legislación del mercado único y concebir ésta de modo que exista un equilibrio entre los derechos económicos y los derechos sociales. Las reformas que se adopten no pueden perder de vista la dimensión social y ciudadana y necesariamente deben incorporar efectos redistributivos y sociales.

Tomando buena nota de lo anterior y para afrontar este crucial y gran desafío, sobre la base del conocido como Informe Monti (2010), en el Consejo Europeo de marzo de 2010 se debatió la Comunicación de la Comisión: «Europa 2020: una estrategia para un crecimiento inteligente, sostenible e integrador». En junio, el Consejo aprobó la nueva Estrategia Europa 2020: una propuesta de política económica para reparar las debilidades estructurales de la UE puestas de manifiesto, por ejemplo, en sus bajos niveles relativos de productividad, inversión en I+D y empleo. Sus tres prioridades esenciales son: alcanzar un creciente inteligente (mediante el desarrollo de una economía basada en el conocimiento y la innovación), un crecimiento sostenible

Unión Europea, Tomo VI (Mercado Único Europeo y Unión Económica y Monetaria), cit., p. 67.

${ }^{26}$ Roca Zamora, A., «El estado del mercado único: un relanzamiento necesario. Balance y desafíos pendientes», Investigaciones Regionales, cit, p. 181. 
(promoviendo una economía que haga un uso más eficaz de los recursos y sea respetuosa con el medio ambiente) y un crecimiento integrador (mediante el fomento de altos niveles de empleo y la mejora de la cohesión económica, social y territorial).

A partir de esas prioridades se han definido cinco objetivos básicos para el conjunto de la Unión Europea:

- Elevar la tasa de empleo del 69\% actual a un mínimo del 75\%.

- Elevar el gasto en investigación y desarrollo (I+D), del actual $2 \%$ al 3\% del PIB de la UE.

- Alcanzar el objetivo «20/20/20» en materia de clima y energía (incluido un incremento al 30\% de la reducción de emisiones si se dan las condiciones para ello). Esto es, reducir las emisiones de gases de efecto invernadero en al menos un 20\% respecto a los niveles de 1990, aumentar el porcentaje de las fuentes de energía renovable en nuestro consumo final de energía hasta un 20\% y en un 20\% la eficiencia energética.

- Reducir la tasa de abandono escolar del 15\% actual a menos del 10\% y aumentar el número de jóvenes titulados universitarios del $31 \%$ actual al $40 \%$.

- Reducir el riesgo de pobreza un $25 \%$, lo que podría suponer 20 millones de personas menos en esa situación.

Para lograr estos objetivos, que se hallan interrelacionados, la Comisión ha propuesto una agenda de actuación compartida para todos los niveles de gobierno (comunitario, nacional, regional y local. A escala europea, los instrumentos clave de esta estrategia son tres: 1) el avance en la realización del mercado único, pues se considera que un mercado único más fuerte, profundo y amplio es crucial para impulsar el crecimiento y la creación de empleo en Europa; 2) el presupuesto comunitario, con sus diferentes instrumentos financieros; y 3) la política exterior de la Unión.

Este relanzamiento político del Mercado Único se concretó, en abril de 2011, en el Acta del Mercado Único de la Comisión, con 12 prioridades que se completaron con el Acta del Mercado Único II (octubre 2012). Prioridades que se fijan para «recuperar un crecimiento sólido, sostenible y equitativo, hacer de los ciudadanos el centro del mercado único y fomentar una mejora de la gobernanza y del diálogo en el mismo».

Estas doce prioridades, simplificando un tanto, las podríamos agrupar en 6 grandes áreas temáticas: A) Desarrollar redes plenamente integradas en el mercado único. B) Promover la movilidad transfronteriza de ciudadanos y empresas. C) Estímulo de la innovación. D) Apoyar la economía digital en Europa. E) Servicios F) Y reforzar el emprendimiento social, la cohesión y la confianza de los consumidores. G) Otras. Vamos a profundizar un poco más en cada una de ellas: 
- Desarrollar redes plenamente integradas en el mercado único

Se requiere el desarrollo de un mercado único completamente integrado para transportes (ferroviario, marítimo y aéreo) y energía. Y ello porque aunque la libre circulación de mercancías es un área muy madura, se hace preciso potenciar sinergias entre el MI y otras políticas de la UE como la de energía, transportes y redes de infraestructuras, auténtico cuello de botella para la total integración del mercado de bienes, pues, por ejemplo, sin un sector de transportes eficaz y armonizado, los elevados y dispares costes de transporte seguirán actuando como una severa barrera no arancelaria, creando dificultades en el funcionamiento práctico del MI e impidiendo su plena potencialidad.

- Promover la movilidad transfronteriza de ciudadanos y empresas.

Mediante la simplificación de los procedimientos para el reconocimiento mutuo de las cualificaciones profesionales y la creación de una tarjeta profesional europea. Y convertir al portal EURES en una potente herramienta electrónica de contratación y de casación de la oferta y demanda de empleo a escala de la UE.

Facilitando el acceso de las PYMES -el 99\% de todas las empresas de la UE- a los mercados de capitales. Concretamente, mediante legislación que facilite que los fondos de capital riesgo que estén establecidos en un Estado miembro puedan invertir en cualquier otro Estado miembro sin obstáculos ni exigencias suplementarias.

$\mathrm{Y}$ ayudando a los empresarios en dificultades a restablecer planes de negocios viables modernizando las normas de insolvencia para facilitar los procedimientos transfronterizos.

\section{- Estímulo de la innovación}

Otro de los grandes retos pendientes del MI. Mediante legislación que establezca una protección unitaria por patente en el mayor número posible de Estados miembros y un sistema unificado de resolución de litigios.

La adopción de una normativa europea que refuerce la lucha contra la piratería y la falsificación. Para ello, es especialmente importante fortalecer el Observatorio Europeo de la Falsificación y la Piratería y mejorar la cooperación entre las autoridades.

Y la modernización del sistema de marcas en Europa para mejorar su protección.

\section{- Apoyar la economía digital}

Garantizando, mediante las oportunas medidas normativas, el reconocimiento mutuo de la identificación y autentificación electrónicas en toda la UE y proceder a la revisión de la Directiva sobre la firma electrónica. 
El objetivo es conseguir una interacción electrónica segura y sin obstáculos.

Facilitando el comercio electrónico y los servicios en línea haciendo más competitivos y eficaces los servicios de pago electrónico en la UE. Promoviendo la facturación electrónica, a fin de generar ahorros a las Administraciones y las empresas y contribuir a reducir el plazo de pago.

\section{- Servicios}

El proceso de integración del mercado de servicios ha seguido un ritmo mucho más lento y dificultoso, con lo que completar el mismo sigue siendo uno de los mayores retos para el mercado único, ya que este sector representa casi un 70\% del PIB europeo y genera nueve de cada diez empleos. Se han previsto como medidas clave las siguientes:

Garantizar la aplicación plena de la Directiva de servicios en todos los Estados miembros, incluidas las disposiciones atinentes a la ventanilla única.

Revisión de la legislación del sistema europeo de normalización para ampliarlo a los servicios y hacer que los procedimientos de normalización sean más eficaces, eficientes y participativos.

Luchar contra las prácticas comerciales desleales entre empresas.

- Reforzar la confianza de los consumidores, el emprendimiento social y la cohesión

Garantizando la puesta en marcha de vías de recurso extrajudiciales que, además de posibilitar una solución fácil, rápida y barata para los consumidores, permita preservar las relaciones de las empresas con su clientela.

Reforzando la confianza de los consumidores en el mercado único. El consumidor debe tener la garantía de que las mercancías que compre sean fiables, independientemente del lugar de su producción. A tal fin se prevé revisar la Directiva sobre la seguridad general de los productos.

Garantizando que los consumidores reciban información fiable sobre el comportamiento medioambiental de los productos, mediante la puesta en marcha de la huella ecológica de los productos.

Garantizando que en todos los modos de transporte se apliquen correctamente los derechos de los pasajeros, incluidos los de las personas con movilidad reducida.

Revisando la Directiva sobre los viajes combinados, particularmente cuando se compren en línea.

Incrementando la protección de los consumidores de productos financieros minoristas, prestándose especial atención a la transparencia de los gastos bancarios y al mercado de los créditos hipotecarios. 
Facilitando el desarrollo de los fondos de inversión solidaria, para favorecer el desarrollo de aquellas empresas que, más allá de la legítima búsqueda del beneficio económico, decidan perseguir también objetivos de interés general que potencien mejoras sociales, éticas o medioambientales.

\section{- Otras varias}

Fiscalidad: Revisión de la Directiva sobre la fiscalidad de la energía. El objetivo es garantizar un tratamiento coherente de las distintas fuentes de energía para tener más en cuenta el contenido energético de cada producto y su nivel de emisiones de $\mathrm{CO} 2$.

Entorno reglamentario de las empresas: simplificación de las directivas sobre las normas contables.

Contratos públicos: revisión y modernización del marco normativo de los contratos públicos.

Por otra parte, además de todo lo anteriormente mencionado, este relanzamiento del MI exige también intensificar la transposición de las Directivas, y mejorar sustancialmente el cumplimiento y la aplicación uniforme de las normas, pues todavía se siguen detectando continuas irregularidades e infracciones. La Comisión persigue activamente estas faltas iniciando procedimientos oficiales de infracción contra los Estados miembros que no cumplen sus obligaciones. Pero dada la lentitud y alto coste de los mismos hay que potenciar los mecanismos extrajudiciales [como la RED SOLVIT (empresas/ciudadanos)] ${ }^{27}$.

Y también es objetivo clave mejorar la gobernanza del MI, lo que requiere un cambio de enfoque centrado en Bruselas a otro de mayor cooperación con los Estados miembros, responsables últimos de la correcta aplicación del ingente acervo comunitario del $\mathrm{MI}^{28}$.

Tampoco hay que olvidar integrar al MI con todas las demás políticas europeas relacionadas, mejorando la coordinación y coherencias de las mismas, a fin de aprovechar las sinergias. El MI no puede desarrollarse adecuadamente sin muchas otras políticas con las que existen complementariedades esenciales, como la política de transportes, infraestructuras, fiscalidad, energía o la política de I+D o la de defensa de la competencia. Y entre ellas hay que destacar la política de cohesión ${ }^{29}$. La libre circulación puede gene-

${ }^{27}$ Roca ZAMORA, A., «La realidad del Mercado Interior», en JordÁn GALdUF, J.M. ${ }^{\text {a }}$ y TAmarit Escalona, C., (Coords.), Economía de la Unión Europea, Thomson Reuters,

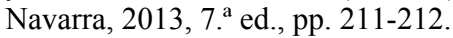

28 Roca Zamora, A., «El estado del mercado único: un relanzamiento necesario. Balance y desafíos pendientes», cit., p. 184.

29 Roca Zamora, A., «El estado del mercado único: un relanzamiento necesario. Balance y desafíos pendientes», cit., pp. 183-184. 
rar desequilibrios territoriales y sociales: a corto plazo se producen costes de ajuste (por ejemplo, pérdidas de empleo en ciertas actividades debido a la deslocalización) y, además, puede existir el riesgo de un agravamiento de los desequilibrios regionales (por procesos de polarización tendentes a incrementar la divergencia entre los espacios centrales y los periféricos). En definitiva, los países y regiones de la UE con una estructura industrial más dinámicas se hallan mejor posicionados para aprovechar los beneficios de un mercado único, mientras que las regiones menos favorecidas temen la «ducha fría» de la competencia exterior y no lograr adaptarse a la nueva realidad ${ }^{30}$.

La política de cohesión social y territorial ha contribuido a difundir los beneficios del MI a todas las regiones. Además, financia las infraestructuras $\mathrm{y}$ redes de transporte y comunicaciones imprescindibles para la interconectividad del MI y su funcionamiento práctico. Se precisa, pues, una política de cohesión fuerte paralelamente al relanzamiento del MI, difícil objetivo dadas las restricciones presupuestarias y la creciente prioridad política de otros objetivos $^{31}$.

\section{OTRAS EXPERIENCIAS EN PROCESO DE CONFORMACIÓN}

Otras organizaciones internacionales también aspiran a la consecución de un Mercado Común, pero por dificultades varias, la mayoría de ellas no pasan de más o menos incipientes Uniones Aduaneras. Entre las más relevantes se encontrarían las siguientes:

\subsection{El Mercado Común Centroamericano (MCCA)}

Está integrado por Guatemala, El Salvador, Honduras, Nicaragua y Costa Rica. Se rige por el Tratado General de Integración Económica Centroamericana de 1960 y sus protocolos modificatorios.

El citado Tratado, suscrito el 13 de diciembre de 1960, contempla la creación de un área de libre comercio y de un arancel común; sienta las bases para una futura consolidación de una Unión Aduanera; y, en sus declaraciones institucionales, la creación de una moneda única que permita la consolidación de una Unión Económica Centroamericana.

Las décadas siguientes a la firma del Tratado se caracterizan por avances centrados tan sólo en el perfeccionamiento de la zona de libre comercio. Con

${ }^{30}$ Roca ZAMORA, A., «La realidad del Mercado Interior», en JoRdÁn GALDUF, J.M. ${ }^{\text {a }}$ y Tamarit Escalona, C., (Coords.), Economía de la Unión Europea, cit., p. 209.

${ }^{31}$ Roca Zamora, A., «El estado del mercado único: un relanzamiento necesario. Balance y desafíos pendientes», cit., p. 184. 
una orientación más pragmática, con la firma del Protocolo de Tegucigalpa (1991) y del Protocolo de Guatemala (1993), se readecuan las normas del Tratado General y se ratifica, nuevamente, el firme compromiso de constituir una Unión Aduanera, maginando la posibilidad de crear una moneda única y constituirse en unión económica. El proceso de consolidación de la Unión Aduanera se alcanzará de forma gradual y progresiva, adaptándose a las circunstancias de cada país, de forma que se faculta a los Estados para que algunos de ellos puedan decidir avanzar con mayor celeridad en el progreso de integración. Así, a tal fin, Guatemala y El Salvador suscriben un acuerdo marco en el año 2000, al que posteriormente se añadirán Nicaragua y Honduras. En el año 2002, con la incorporación de Costa Rica, los presidentes de la región aprueban un Plan de Acción para acelerar la Unión Aduanera. Y en diciembre de 2007, el acuerdo marco para el establecimiento de la Unión Aduanera Centroamericana, acuerdo que deberá ser ratificado por las respectivas asambleas legislativas.

Aunque en los últimos años, pues, ha registrado mejoras considerables en su apuesta por profundizar en el proceso de integración económica regional, su posición actual no pasa de cercana al estadio de unión aduanera plena $^{32}$.

\subsection{La Comunidad del Caribe (CARICOM)}

Los miembros de pleno derecho son: Antigua y Barbuda, Barbados, Belice, Dominica, Granada, Guyana, Jamaica, Montserrat, Saint Kitts y Nevis, Santa Lucía, San Vicente y las Granadinas, Trinidad y Tobago. Aruba, Colombia, Curazao, México, Puerto Rico, Saint Martin y Venezuela son países observadores. Su sede se encuentra en Georgetown, Guyana.

Como objetivos fundamentales que persigue esta Organización hay que destacar: el fomento del grado de integración económica mediante el establecimiento de un Mercado Común; la expansión de la cooperación funcional en campos como la educación, la saludo o el transporte; y la coordinación de la política exterior entre los Estados independientes de la Comunidad.

En las recientes cumbres se verifica un firme empeño de replantear profundamente la integración y de acelerar la configuración del Mercado Común, pero aún hay que esperar resultados prácticos más concretos en este sentido ${ }^{33}$.

${ }^{32}$ Moslares García, C.; Ramírez Roma, X.; Reyes, G., «¿Están los países del Mercado Común Centroamericano preparados para una mayor integración regional?», ECONOMÍAunam, vol. 8, núm. 22, pp. 1 y 27.

33 PÉRez GonzÁlez, M., «Las Organizaciones Internacionales en América (II)», en Diez de Velasco, M., Las Organizaciones Internacionales, Tecnos, 2013, pp. 795-798. 


\subsection{La Comunidad Andina}

Formada por Bolivia, Colombia, Ecuador y Perú. Según el art. 1 del Acuerdo de Integración Subregional o Acuerdo de Cartagena:

«El presente Acuerdo tiene por objetivos promover el desarrollo equilibrado y armónico de los Países Miembros, en condiciones de equidad, mediante la integración y la cooperación económica y social; acelerar su crecimiento y la generación de ocupación; facilitar su participación en el proceso de integración regional, con miras a la formación gradual de un mercado común latinoamericano.

Asimismo, son objetivos de este Acuerdo propender a disminuir la vulnerabilidad externa y mejorar la posición de los Países Miembros en el contexto económico internacional; fortalecer la solidaridad subregional y reducir las diferencias de desarrollo existentes entre los Países Miembros.

Estos objetivos tienen la finalidad de procurar un mejoramiento persistente en el nivel de vida de la Subregión».

Los esfuerzos realizados hasta el momento por los países andinos en estos ámbitos no han permitido aún obtener los resultados esperados. La integración económica andina debe hacer frente a dificultades de diversa índole: obstáculos geográficos (barreras naturales, mala navegabilidad de los ejes fluviales), tensiones políticas persistentes (riesgos de extensión del conflicto colombiano, inestabilidad en Bolivia y Ecuador), fuertes desigualdades en términos de desarrollo, atracción ejercida por las otras estructuras económicas regionales (Estados Unidos, MERCOSUR) y, la salida de Venezuela. Todavía no cuenta con un Mercado Común plenamente constituido ${ }^{34}$.

\subsection{El Mercado Común del Sur (MERCOSUR)}

El art. 1 del Tratado de Asunción recoge el firme propósito de los Estados participantes (Argentina, Brasil, Paraguay y Uruguay) para constituir el 31 de diciembre de 1994 el Mercado Común del Sur (MERCOSUR). Éste implica:

«a) La libre circulación de bienes, servicios y factores productivos entre los países, a través, entre otros, de la eliminación de los derechos aduaneros y restricciones no arancelarias a la circulación de mercaderías y de cualquier otra medida equivalente;

b) El establecimiento de un arancel externo común y la adopción de una política comercial común en relación a terceros Estados o agrupacio-

${ }^{34}$ Más ampliamente; DA Silva, J., «La Comunidad Andina», Mediterráneo Económico 22, 2012; y PÉrez GonzÁlez, M., «Las Organizaciones Internacionales en América (III)», en Diez DE Velasco, M., Las Organizaciones Internacionales, cit., pp. 805-818. 
nes de Estados y la coordinación de posiciones en foros económico-comerciales regionales o internacionales;

c) La coordinación de políticas macroeconómicas y sectoriales entre los Estados Partes: de comercio exterior, agrícola, industrial, fiscal, monetaria, cambiaria y de capitales, de servicios, aduanera, de transportes y comunicaciones y otras que se acuerden, a fin de asegurar condiciones adecuadas de competencia entre los Estados Partes;

d) El compromiso de los Estados Partes de armonizar sus legislaciones en las áreas pertinentes, para lograr el fortalecimiento del proceso de integración».

A nivel interno, el desarme arancelario es ya casi completo, y a nivel externo la Unión Aduanera está vigente desde el 1 de enero de 1995, aunque todavía funciona de forma imperfecta. Por tanto, y a despecho de su título (Mercado Común del Sur), el proceso de integración del MERCOSUR dista aún de alcanzar el estadio de un verdadero mercado común, quedándose en una incipiente Unión Aduanera.

Entre sus principales logros está el haber alcanzado en pocos años, por su potencial económico, una importante relevancia económica internacional, representando un tercio del comercio exterior latinoamericano y recibiendo un tercio de la inversión extranjera directa en la región. También su importante papel en la consolidación democrática de sus países miembros (como, por ejemplo, a través de la Cláusula democrática de la X Reunión, en la Cumbre de junio de 1996, tras la tentativa de golpe de Estado de Paraguay en abril de dicho año; y el Protocolo de Ushua sobre Compromiso Democrático suscrito en junio de 1998. En cuanto a los desafíos pendientes más inmediatos, la consolidación y el perfeccionamiento de la Unión Aduanera y la reducción de las asimetrías de las economías de sus Estados miembros, lo que dificulta enormemente la coordinación de políticas necesarias en todo proceso de integración. También el desarrollo institucional, fortaleciendo su autonomía para agilizar y potenciar la integración ${ }^{35}$.

\subsection{La Comunidad Económica Africana (CEA)}

Forman parte de esta Organización los 53 Estados miembros de la Unión Africana (UA). Los fines que persigue se enuncian de manera bastante vaga en el Tratado de Abuja (1991), y están destinados a articular un espacio económico africano a construir, según su art. $6 .^{\circ}$, en un plazo de treinta y cuatro

${ }^{35}$ Pérez GonzÁlez, M., «Las Organizaciones Internacionales en América (III)», en Diez de Velasco, M., Las Organizaciones Internacionales, cit., pp. 818-831. Más ampliamente, Da Silva Bichara, J., «Integración latinoamericana: de ALALC al Mercosur», Mediterráneo Económico 22, 2012. 
años desde su entrada en vigor. Están previstas seis etapas encaminadas a: reforzar las Comunidades regionales africanas ya existentes y crear otras nuevas donde no existan; constituir zonas de libre comercio regionales; establecer uniones aduaneras regionales; crear una unión aduanera continental; realizar un mercado común africano; crear una Comunidad económica en sentido propio.

Cada una de estas fases cuenta con un período máximo de realización sin que se haya previsto el paso automático de una a otra que, en todo caso, es competencia de la Conferencia previa recomendación del Consejo.

La CEA se encuentra aún en sus primeros inicios, lastrada por el desequilibrio entre la complejidad de su estructura institucional y el contenido real de sus funciones ${ }^{36}$.

\subsection{El Mercado Común de África Central y Oriental (COMESA)}

El 10 de enero de 1993 fue firmado en Kampala un Tratado de integración comercial entre los países de esta zona de África. Sus Estados miembros son: Burundi, Comoras, República Democrática del Congo, Djibuti, Egipto, Eritrea, Etiopía, Kenia, Libia, Madagascar, Malawi, Mauricio, Ruanda, Seychelles, Sudán, Swazilandia, Uganda, Zambia y Zimbabwe. Bostswana y Sudáfrica están en proceso de adhesión.

Las actividades de la Organización van a desplegarse en cinco ámbitos principales: acuerdos de libre comercio que comprenden el libre movimiento de bienes y servicios producidos dentro del Mercado Común; una unión aduanera con una tarifa externa común; la armonización de macropolíticas para la inversión y liberalización, incluyendo el libre movimiento de capitales; la coordinación de políticas sectoriales e intersectoriales para la producción, comercio y desarrollo; y el libre movimiento de personas y trabajadores, lo que incluye el derecho de establecimiento. Objetivos pues muy ambiciosos sobre el papel y que vienen a suponer un paso adelante en el proceso de cooperación entre estos países iniciado en julio de 1979, pero lejos de su definitiva consecución ${ }^{37}$.

\subsection{La Asociación de Naciones del Asia Sudoriental (ASEAN)}

Los miembros originarios de esta Organización fueron los Estados que suscribieron la Declaración de Bangkok de 1967: Indonesia, Malasia, Filipi-

${ }^{36}$ Sobrino HerediA, J.M., «Las Organizaciones Internacionales en el Mundo Árabe e Islámico y las Organizaciones Internacionales en Áfric»»», en DiEZ DE VELASCO, M., Las Organizaciones Internacionales, cit., pp. 867-868.

${ }^{37}$ Ibídem, pp. 884-885. 
nas, Singapur y Tailandia. A estos Estados se les unió posteriormente Brunei Durassalam, Vietnam, Birmania, Laos, Myanmar y Camboya. PaupasiaNueva Guinea tiene estatuto de país observador y Corea del Sur dispone de un estatuto especial.

Las dos grandes motivaciones de esta cohesión regional han sido: el fomento de la estabilidad del Sudeste asiático frente al avance comunista en la región y a los movimientos guerrilleros en el interior de sus países miembros, constituyendo un foco de conciliación multilateral y freno de los enfrentamientos por controversias territoriales entre sus Estados miembros; y la cooperación económica que se ha ido acrecentando con la consolidación de la Organización. Así, en la Cumbre que tuvo lugar en Bali el 7 y 8 de octubre de 2003, se lanzó la idea de la creación de un Mercado Común para 202038.

\subsection{El Consejo de Cooperación de los Estados Árabes del Golfo (CCG)}

Integrado por Arabia Saudí, Kuwait, Emiratos Árabes Unidos, Bahrein, Omán y Qatar. Desde sus orígenes ha recorrido un largo camino. Si bien inicialmente el objetivo que convocó a estos Estados fue el de cooperar en materia militar y de seguridad, con el tiempo las áreas de trabajo conjunto se fueron ampliando, prestando mayor atención a la cooperación en otros ámbitos, particularmente el económico. En este ámbito, en 1981 se firmó el Estatuto Económico Unificado, documento que prevé la conformación de una Zona de Libre Comercio, reconoce la libertad de movimiento, trabajo y residencia de los ciudadanos de los Estados Parte, propone la armonización de las legislaciones relativas a la extracción y el comercio del petróleo, así como también coordinar las posiciones de los seis Estados en esta materia frente a los organismos internacionales, e insta a la coordinación de políticas financieras, monetarias y bancarias con vistas al establecimiento de una moneda común.

Los logros económicos iniciales de este proceso de integración fueron escasos. Entre 1982 -año en el cual entra en vigor la Zona de Libre Comercio-y 2000 el comercio intraregional sólo creció del 5\% al 7\%. La decepción quedó elocuentemente reflejada en las palabras del príncipe heredero de Arabia Saudita Abadala bin Abd Al Aziz Al Saud en la inauguración de la reunión del Consejo Supremo llevada a cabo en diciembre de 2001 en la ciudad de Muscat «No hemos sido capaces de alcanzar los objetivos que buscamos cuando formamos este Consejo... No hemos alcanzado un Mercado Común ni siquiera hemos formulado una posición política común...Nues-

38 Sobrino Heredia, J.M., «Las Organizaciones Internacionales en Asia y Oceanía», en Diez de Velasco, M., Las Organizaciones Internacionales, cit., pp. 891 y 895. 
tro gran apego al concepto tradicional de soberanía es el mayor obstáculo que tenemos en nuestro esfuerzo de integración»».

No obstante la desilusión, y después de dos días de negociaciones, el 31 de diciembre de 2001 los miembros firmaron el nuevo Acuerdo Económico Unificado, basado en el antiguo, pero agregándole algunos objetivos. Este acuerdo consta de 9 capítulos y 33 artículos en los cuales se busca una Unión Aduanera, un Mercado Común, y una Unión Monetaria y Económica. Aun así todavía se está en proceso de conformar un Mercado Común, descartándose también por el momento la implementación de una moneda común ${ }^{39}$.

\section{TITLE: The Common Market}

RESUMEN: El presente artículo analiza la modalidad de integración económica supranacional conocida como Mercado Común. Pese a que otras organizaciones internacionales también aspiran a su consecución, el Mercado Común o Interior Europeo es aún, a saber, su única manifestación exitosa, aunque no plenamente acabada. Su concepto, evolución y desafios pendientes, junto con otras experiencias en proceso de conformación constituyen nuestro objeto de estudio.

PALABRAS CLAVE: Mercado Común, integraciones económicas supranacionales.

ABSTRACT: This article analyzes the form of supranational economic integration, known as Single Market. Despite the fact that other international organizations also aspire to achieve it, the EU's Single Market or EU's Internal Market is still, namely, its only successful manifestation, although not fully finished. Its concept, evolution and challenges, together with other experiences in forming process constitute our object of study.

KEY WORDS: Single Market, supranational economic integrations.

RECIBIDO: 03.06.2016

ACEPTADO: 22.06.2016

39 Ibidem, pp. 898-900. Vid. también, FABANI, O., «El Consejo de Cooperación de Estados Árabes del Golfo: un análisis de su evolución a 30 años de su conformación», $V$ Congreso de Relaciones Internacionales, La Plata 24, 25 y 26 de noviembre de 2010, Octava Jornada de Medio Oriente, <http://sedici.unlp.edu.ar/bitstream/handle/10915/39836/Documento_completo.pdf?sequence=1>, p. 19. Y BARTESAGHI, I. Y Mangana, S., «El Consejo de Cooperación del Golfo (CCG): Las relaciones con el Mercosur, XI Seminario de Relaciones Internacionales ISRI 2014, <http://ucu.edu.uy/sites/ default/files/Consejo\%20de\%20Cooperaci\%C3\%B3n\%20del\%20Golfo.pdf>, p. 4. 